\title{
Beta-Glucan-Rich Extract from Pleurotus sajor-caju (Fr.) Singer Prevents Obesity and Oxidative Stress in C57BL/6J Mice Fed on a High-Fat Diet
}

\author{
G. Kanagasabapathy, ${ }^{1,2}$ S. N. A. Malek, ${ }^{1,3}$ A. A. Mahmood, ${ }^{1,2}$ K. H. Chua, ${ }^{1,2}$ \\ S. Vikineswary, ${ }^{1,3}$ and U. R. Kuppusamy ${ }^{1,2}$ \\ ${ }^{1}$ Mushroom Research Centre, University of Malaya, 50603 Kuala Lumpur, Malaysia \\ ${ }^{2}$ Department of Biomedical Science, Faculty of Medicine, University of Malaya, 50603 Kuala Lumpur, Malaysia \\ ${ }^{3}$ Institute of Biological Sciences, Faculty of Science, University of Malaya, 50603 Kuala Lumpur, Malaysia
}

Correspondence should be addressed to U. R. Kuppusamy; umah@um.edu.my

Received 14 February 2013; Revised 10 April 2013; Accepted 14 April 2013

Academic Editor: Menaka C. Thounaojam

Copyright ( 2013 G. Kanagasabapathy et al. This is an open access article distributed under the Creative Commons Attribution License, which permits unrestricted use, distribution, and reproduction in any medium, provided the original work is properly cited.

\begin{abstract}
Mushrooms have been used in folk medicine for thousands of years. In this study, the effect of $\beta$-glucan-rich extract of $P$. sajor-caju (GE) on lipid lowering and antioxidant potential was assessed in C57BL/6 J mice fed on a high-fat diet. Obesity was induced in C57BL/6J mice by feeding a high-fat diet. The control groups in this study were ND (for normal diet) and HFD (for high-fat diet). The treated groups were ND240 (for normal diet) $(240 \mathrm{mg} / \mathrm{kg} \mathrm{b.w}$ ) and HFD60, HFD120, and HFD240 (for high-fat diet), where the mice were administrated with three dosages of GE (60, 120, and $240 \mathrm{mg} \mathrm{GE} / \mathrm{kg}$ b.w). Metformin ( $2 \mathrm{mg} / \mathrm{kg}$ b.w) served as positive control. GE-treated groups showed significantly reduced body weight, serum lipid, and liver enzymes levels. GE also attenuated protein carbonyl and lipid hydroperoxide levels by increasing the enzymic antioxidants (SOD, CAT, and GPx) activities in the mice. GE-treated groups induced the expression of hormone sensitive lipase (HSL) and adipose triglyceride lipase (ATGL) while downregulated the expression of peroxisome proliferator-activated receptor gamma (PPAR- $\gamma$ ), sterol regulatory binding protein-1c (SREBP-1c), and lipoprotein lipase (LPL). Hence, GE prevented weight gain in the mice by inducing lipolysis and may be valuable in the formulation of adjuvant therapy for obesity.
\end{abstract}

\section{Introduction}

Obesity has reached epidemic proportions and is a major contributor to the global burden of chronic disease and disability because of its increasing prevalence in all age groups, sex, and race with the changes of lifestyles and dietary intake. A recent statistical report by the World Health Organization showed that one out of ten adults were overweight; hence, there are more than one billion overweight adults $[1,2]$. Besides that, according to the National Health and Morbidity Surveys (2011), 15.1\% of Malaysians aged 18 and above were obese thus Malaysia has the highest rate of obesity in south east Asia and the 6th in Asia. Obesity is a chronic metabolic disorder that results from the disequilibrium between energy intake and energy expenditure.
It is characterized by enlarging fat mass and elevated lipid concentration in blood. The amount of fat mass is increased when the number and size of adipocytes are increased by proliferation and differentiation [3]. The obvious alternatives for the treatment of obesity are diet, exercise, and surgical intervention such as bariatric surgery, Roux-en- $Y$ gastric bypass, gastric banding, and sleeve gastrectomy. However, it is proven to be successful only in a small minority of the population $[4,5]$. Drugs that are currently available for the management of obesity, include orlistat (Xenical) which reduces intestinal fat absorption through inhibition of pancreatic lipase and sibutramine (Reductil), and appetite suppressant [2] which was found to cause numerous side-effects which include valvular heart disease, high blood pressure, dry mouth, constipation, and headache [6]. Multiple risk factor 
syndrome or metabolic syndrome such as insulin resistance [7], diabetes mellitus [8], cardiovascular disease, stroke, hypertension [9], and dyslipidemia [10] is a growing medical problem in industrialized countries. Obesity is the central and causal component in this syndrome [11]. Furukawa et al. [11] reported that in obese individuals, elevated reactive oxygen species (ROS) upregulates the expression of NADPH oxidase, establishing a vicious cycle that augments oxidative stress in adipocytes and blood circulation. The ROS will increase the expression of chemoattractants such as monochemoattractant proteins-1 (MCP-1), by-products of lipid oxidation (lipid hydroperoxides and malondialdehyde (MDA)), and protein oxidation (protein carbonyl) [12, 13] which are linked with systemic inflammation which then lead to the development of metabolic syndrome. However, it is also well reported that antioxidants can inactivate these ROS and thus prevent metabolic deregulation including metabolic syndrome [14].

Mushrooms are well known for their medicinal properties and have been widely used in traditional medicine. The medicinal effects of mushrooms include antioxidant, antiviral, antibacterial, antifungal, antiparasitic, detoxification, immunomodulatory, antitumor, radical scavengers, antiinflammatory, antihyperlipidemic, or antihypercholesterolemic, hepatoprotective, and antidiabetic [14]. In Malaysia, the genus Pleurotus (oyster mushroom) which has been shown to have definite nutritive (high quality proteins, vitamins, and very little lipids or starch) and medicinal values is widely cultivated. This mushroom is mostly popular in countries such as India, China, and Japan and is reported to be able to reduce the cholesterol level in blood [15] and prevent hyperglycemia, insulin resistance, and inflammation in adipose tissue [16]. Pleurotus mushroom is rich in fiber yet low in calories and fat, and it has been cited as a potential weight-loss aid. The dietary fibers in the mushroom consist of chitin, hemicelluloses, mannans, and $\beta$-glucans. Beta-glucans are polysaccharides with glucose residue linked by beta glycosidic bonds. The fermentability of $\beta$-glucans and their ability to form highly viscous solutions in the human gut may constitute the basis of their antiobesity benefits [17]. Natural products containing $\beta$ glucans have been used for thousands of years, but $\beta$-glucans were only identified as active components recently. Therefore, this study was undertaken to investigate the effects of $\beta$ glucan-rich extract (GE) from $P$. sajor-caju on prevention of obesity and oxidative stress in C57BL/6J mice fed on a highfat diet.

\section{Materials and Methods}

2.1. Mushroom Samples. All necessary permits and permission for the collection of materials for the described field study were obtained, and the party involved is duly acknowledged. Fresh fruiting bodies of Pleurotus sajorсаju $(10 \mathrm{~kg})$ were grown and collected from Mr. Kuan Kek How mushroom farm in Semenyih, Selangor Darul Ehsan, Malaysia. Authentication of $P$. sajor-caju was carried out by the Mushroom Research Centre (MRC), University of Malaya, and a voucher material (KUM 50082) for this study was deposited at the MRC culture collection.
2.2. Isolation and Purification of GE. The isolation and purification of GE were carried out based on the method described by Roy et al. [18]. The $\beta$-glucan level in GE was estimated using the $\beta$-glucan kit (specific for mushroom and yeast) purchased from Megazyme International (Ireland). The enzyme kit contains exo-1,3- $\beta$-glucanase, $\beta$ glucosidase, amyloglucosidase and invertase, glucose determination reagent (GOPOD-glucose oxidase, peroxidase, and 4-aminoantipyrine), and glucose standard solution. The estimation of total glucan content was done by hydrolysing GE with $37 \%$ hydrochloric acid (v/v) for 45 minutes at $30^{\circ} \mathrm{C}$ and continued for 2 hours at $100^{\circ} \mathrm{C}$. After neutralization with $2 \mathrm{M}$ potassium hydroxide, glucose hydrolysis was carried out using a mixture of exo- $\beta$-(1-3)-D-glucanase and $\beta$ glucosidase in sodium acetate buffer $(\mathrm{pH}$ 5.0) for 1 hour at $40^{\circ} \mathrm{C}$. To measure the total glucan content, glucose oxidaseperoxidase mixture was added to GE and incubated for 20 minutes at $40^{\circ} \mathrm{C}$. The absorbance of the resulting colour complex was measured using a spectrophotometer (BioTek Instruments Inc, USA) at $510 \mathrm{~nm}$. The $\alpha$-glucan content was estimated according to the same method as described above after enzymatic hydrolysis with amyloglucosidase and invertase. The $\beta$-glucan content was calculated by subtracting the $\alpha$-glucan from the total glucan content. Glucan content was expressed as percentage (w/w) of dry weight (DW).

2.3. Animals and Ethics Statement. This study was conducted in conformity with the policies and procedures of the Animal Care and Use Guidelines of Faculty of Medicine, University of Malaya, with reference to the 8th edition of Guide for the Care and Use of Laboratory Animals by the Institute of Laboratory Animal Research, National Academy of Science, USA. The animal ethics approval was obtained from Animal Care and Use Committee of Faculty of Medicine, University of Malaya (IACUC, UM) (approval number: ISB/14/07/2010/GK [R]). Female C57BL/6j mice (7 weeks old) were purchased from BioLasco Laboratory, Taiwan. The animals were maintained in stainless steel wire mesh cages in a room kept at $21^{\circ} \mathrm{C}$ with a standard condition of 12-hour light/dark cycle (light period: 8:00-20:00 hour) with free access to food and water which were provided fresh every day.

2.4. Experimental Design. After one week of acclimatisation, the mice were randomly assigned (based on weight) into seven groups $(n=6)$. Table 1 shows the type of diet and concentration of GE administered to each group. On caloric basis, the normal diet contained 5\% fat, 69.2\% carbohydrate, and $25.8 \%$ protein whereas the high-fat diets (TestDiet, USA) comprised $45 \%$ of fat $(46.1 \%$ fat from lard, $35.8 \%$ carbohydrate, and $18.1 \%$ protein) and $60 \%$ of fat $(61.6 \%$ fat from lard, $20.3 \%$ carbohydrate, and $18.1 \%$ protein). GE was administered thrice a week via epigastric route using a feeding needle (size 20) to groups ND240, HFD60, HFD120, and HFD240 for 16 weeks. In this study, metformin ( $2 \mathrm{mg} / \mathrm{kg} \mathrm{b.w})$ was used as the positive control (HFDMET) since metformin has been reported to have comparable effects with orlistat (antiobesity drug) [19], and it is also widely used to treat type 2 diabetes which is closely associated with obesity [11]. After 7 weeks 
TABLE 1: Type of diet and concentration of GE/metformin administrated to each group.

\begin{tabular}{ccl}
\hline Type of diet & Groups & Treatment \\
\hline Normal diet & ND & $\begin{array}{l}\text { Normal diet only }+ \text { saline } \\
\text { Normal diet }+240 \mathrm{mg} / \mathrm{kg} \text { of body } \\
\text { weight GE }\end{array}$ \\
\hline High-fat diet & HFD120 & $\begin{array}{l}\text { High-fat diet only }+ \text { saline } \\
\text { High-fat diet }+60 \mathrm{mg} / \mathrm{kg} \text { of body } \\
\text { weight of GE } \\
\text { weight of GE }+120 \mathrm{mg} / \mathrm{kg} \text { of body } \\
\text { High-fat diet }+240 \mathrm{mg} / \mathrm{kg} \text { of body } \\
\text { weight of GE } \\
\text { High-fat diet }+2 \mathrm{mg} / \mathrm{kg} \text { of body } \\
\text { weight of metformin }\end{array}$ \\
& HFD240 &
\end{tabular}

of feeding with $45 \%$ of fat, the animal diet was substituted with $60 \%$ of fat for groups HFD, HFD60, HFD120, HFD240 and HFDMET. The diet for groups ND and ND240 was not altered throughout the experiment. For the normal diet group, only $240 \mathrm{mg} / \mathrm{kg}$ of body weight of GE (highest dose) was administrated to the mice in order to reduce the usage of mice.

2.4.1. Sample Collection and Analytical Methods. Body weight and food consumption were monitored daily. During the experimental period, urine was collected from each group weekly (every Monday morning at 10:00 hour). At the end of the 16 weeks, the mice were anesthetized with ether after withholding food for 12 hours and were sacrificed by aortic exsanguination. Blood samples were collected in a SST glass serum tube with gold BD Hemogard closure (BD Vacutainer, USA). Serum samples were separated after centrifugation at $2400 \times \mathrm{g}$ for 15 minutes. The serum samples from each mouse (within a group) were pooled together in order to have sufficient serum for further analysis. The pooled serum samples were sent to the Clinical Diagnostic Laboratory Unit, University Malaya Medical Centre, for the serum lipid and liver analysis. Immediately after blood collection, the liver and kidney were perfused in-situ with ice-cold saline. The weight of the liver and kidney of mice from each group were recorded. Eight $\mathrm{mL}$ of ice-cold phosphate buffer saline (PBS) was added to one gram of liver or kidney. The samples were then homogenized using a homogenizer (WiseMix HG-15A, Germany). Adipose tissues were removed and stored in RNAlater solution (Applied Biosystems, USA) and refrigerated at $4^{\circ} \mathrm{C}$ overnight. All samples were then stored at $-80^{\circ} \mathrm{C}$ until further analysis was carried out.

2.5. Urinary Oxidative Indices Measurement. The protein carbonyl content (AOPP) was determined as previously described [20]. Chloramine-T solution of known concentrations ( 0 to $500 \mu \mathrm{M}$ ) was used as a standard for the estimation of AOPP concentration, and the result was expressed as $\mu \mathrm{M}$ of chloramine-T. Lipid hydroperoxide level was determined based on the method described by
Esterbauer and Cheeseman [21] with modifications. 1,1,3,3Tetraethoxypropane (TEP) solution of known concentration ( 2.5 to $20 \mu \mathrm{M}$ ) was used as a standard for quantification, and the result was expressed as $\mu \mathrm{M}$ of TEP. The DNA damage level was quantified using 8-hydroxy-2-deoxy-Guanosine (8-OHdG) EIA kit (Cayman Chemical, USA). 8-Hydroxy2-deoxy-Guanosine hydroxyl EIA standard $(10.3 \mathrm{pg} / \mathrm{mL}$ to $30 \mathrm{ng} / \mathrm{mL}$ ) was used for quantification, and the result was expressed as $\mathrm{pg} / \mathrm{mL}$.

2.6. Enzymic Antioxidant Activity Measurement. The kidney and liver tissue homogenates were used to measure the activities of superoxide dismutase (SOD [EC-1.15.1.1]), glutathione peroxidase (GPx [EC-1.11.1.9]), and catalase (CAT [EC-1.11.1.6]). Commercially available kits were used for SOD, CAT, and GPx assays (Calbiochem, Germany). The protein content of the homogenates was determined using the BioRad Protein Assay (Barcelona, Spain) [22] with bovine serum albumin as a standard. Enzyme activities were expressed in units per milligram of protein. One unit of SOD activity was defined as the amount of enzyme that exhibited $50 \%$ dismutation of the superoxide radical. One unit of CAT activity was defined as the amount of enzyme that caused the formation of $1.0 \mathrm{nmol}$ formaldehyde per min. The unit of GPx activity was expressed as nanomoles of NADPH per min (calculated using an extinction coefficient of $0.00373 \mu \mathrm{M}^{-1}$ ).

2.7. Lipid Peroxidation Assay (LPO). The LPO assay was determined according to the modified method of Kuppusamy et al. [23] based on thiobarbituric acid reaction in which MDA was used as an index of lipid peroxidation. Trichloroacetic acid (15\%) and thiobarbituric acid (1\%) were added to the tissue homogenates in triplicates. The mixtures were incubated in boiling water bath for 10 minutes and were centrifuged at $6000 \times \mathrm{g}$ for 10 minutes to remove the sediments. The absorbance was read at $532 \mathrm{~nm}$ using a spectrophotometer (Bio-Tek Instrument Inc., USA). 1,1,3,3Tetraethoxypropane (TEP) solution of known concentration (2.5 to $20 \mu \mathrm{M}$ ) was used as a standard for quantification, and the result was expressed as $\mathrm{mmol} / \mathrm{L}$ of TEP.

2.8. Gene Expression Using Real Time: RT-PCR. The total RNA was isolated from the adipose tissue using Ambion RNAqueous-Micro Kit (Applied Biosystems, USA). The purity of recovered total RNA was estimated by calculating the ratio of absorbance reading of $260 \mathrm{~nm}$ and $280 \mathrm{~nm}$. The integrity of RNA was estimated using Agilent 2100 Bioanalyzer (Applied Biosystems, USA). Purified RNA with an $A_{260} / A_{280}$ ratio between 1.8-2.0 and RIN values 8-10 was further used to synthesize complementary DNA (cDNA) by polymerase chain reaction (PCR) approach. High Capacity cDNA Reverse Transcription Kit (Applied Biosystems, USA) which contained all reagents needed (RT buffer, dNTP mix, random primers, Multiscribe reverse transcriptase enzyme, and nuclease free water) for reverse transcription (RT) of total RNA to single-stranded cDNA was used in this study. The mixture was then loaded into a thermal cycler (Eppendorf, USA), and PCR was carried out according to optimized 
TABLE 2: Genes investigated.

\begin{tabular}{lccc}
\hline Number & Gene name and abbreviation & Assay ID & Accession number \\
\hline 1 & Adipose triglycerides lipase (ATGL/Pnpla2) & Mm 00503040_m1 & NM_025802 \\
2 & Hormone sensitive lipase (HSL/Lipe) & Mm 00495359_m1 & NM_001039507 \\
3 & Lipoprotein lipase (LPL) & Mm 00434770_m1 & NM_008509.2 \\
4 & Peroxisome proliferator-activated receptor $\gamma($ PPAR- $\gamma$ ) & Mm 01184322_m1 & NM_011146 \\
5 & Sterol regulatory binding protein (SREBP-1c) & Mm 00550338_m1 & NM_011480.3 \\
\hline
\end{tabular}

General abbreviation of genes selected for this study and corresponding assay ID and accession number was obtained from the Applied Biosystems website and NCBI database. Assay ID refers to the Applied Biosystems Gene Expression Assays inventoried kits with proprietary primer and TaqMan probe mix. Assay ID with "Mm" is referred to as "Mus musculus." All Gene Expression Assay kits indicated are FAM/MGB probed.

thermal cycling conditions provided by the manufacturer. Table 2 shows the list of genes investigated in this study and the corresponding accession numbers. Endogenous control used in this study was eukaryotic $18 \mathrm{~S}$ rRNA with FAM/MGB probe. All TaqMan (Applied Biosystems, USA) probes used in this investigation were labeled with FAM reporter dye at the $5^{\prime}$ end and a MGB quencher at the $3^{\prime}$ end. The quantification approach used was the comparative CT method, also known as $2^{-\Delta \Delta \mathrm{Ct}}$ method [24].

2.9. Statistical Analysis. Data are shown as mean \pm SD of triplicate assays. One-way analysis of variance was used to estimate the significant differences between groups. Statistical significance was accepted at $P<0.05$. Duncan's multiple range tests (DMRT) was used to determine the significant differences between groups. Statgraphics Plus software (version 3.0, Statistical Graphics Corp., Princeton, NJ, USA) was used for all statistical analyses. All figures were drawn using GraphPad Prism 5 (GraphPad Software Inc., California, USA).

\section{Results and Discussion}

3.1. Weight and Estimation of $\beta$-Glucan Concentration in GE. Fresh P. sajor-caju $(5.5 \mathrm{~kg})$ was boiled for 8 hours to obtain $12.31 \mathrm{~g}$ of GE. The concentration of total glucan in GE was $85.95 \%(\mathrm{w} / \mathrm{w})$ meanwhile the concentrations of $\alpha$ glucan and $\beta$-glucan were $5.4 \%(\mathrm{w} / \mathrm{w})$ and $80.55 \%(\mathrm{w} / \mathrm{w})$ which corresponded to $0.01 \%$ and $1.5 \%$ in fresh mushroom, respectively [17].

3.2. Effects of GE on the Changes in Body Weight and Serum Lipid Levels. The test compounds (GE/metformin/vehicle) were only administered thrice a week to the mice in order to avoid physical stress. The mean food consumption was not significantly different between high-fat diet-treated mice and high-fat diet plus GE-treated mice. Figure 1 shows the effects of GE and metformin on body weight changes in the mice. The body weight in the ND group gradually increased during the 16-week period. In contrast, the body weight of mice in the HFD group showed a rapid increase of body weight. The descending order of the percentages of weight gain in each group was HFD > HFD60 > HFD120 > HFDMET > ND $>$ HFD240 > ND240. The mice in HFD60, HFD120, and HFD240 groups had $27.55 \%, 36.69 \%$, and $39.76 \%$ lower body

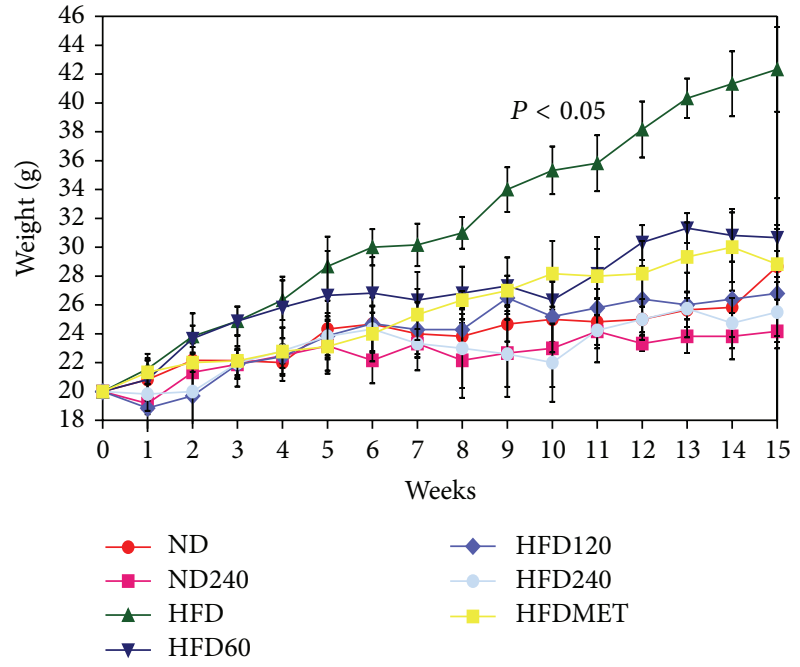

FIGURE 1: Effects of GE and metformin on body weight changes in $\mathrm{C} 57 \mathrm{BL} / 6 \mathrm{~J}$ mice fed on a high-fat diet or normal diet. The concentrations of GE were 60, 120, and $240 \mathrm{mg} / \mathrm{kg} /$ day. Metformin $(2 \mathrm{mg} / \mathrm{kg} /$ day $)$ was used as positive control. Values expressed are means \pm S.D of ( $n=6$ per group) measurements.

weight, respectively, compared to HFD group. HFDMET group showed $31.90 \%$ lower body weight compared to HFD group; hence, the potential weight lowering effect of GEtreated groups were comparable to HFDMET group. Obesity has been associated with increased triglycerides (TG), very low-density lipoprotein (VLDL), total cholesterol (TC), and decreased high-density lipoprotein cholesterol (HDL-c) and thus is also a risk factor of cardiovascular disease [25]. Table 3 shows the serum lipid profile which includes the levels of TG, TC, HDL-c, low-density lipoprotein cholesterol (LDLc), and atherogenic index (AI). In HFD control group, the TG level was increased by $33.3 \%$, TC increased by $40 \%$, HDL-c increased by $34.6 \%$, and LDL-c increased by $171.4 \%$ compared to those in the ND group, thus the mice in HFD were considered to be hyperlipidemic. Meanwhile, mice in HFD60, HFD120, and HFD240 groups showed considerably reduced levels of TG, TC, and LDL-c compared to the HFD group, and this effect was dose dependent. The percentages of reduction for TG, TC, and LDL-c levels in HFD60 were 12.5\%, $7.1 \%$, and $60.5 \%$, respectively. The percentages of reduction for TG, TC, and LDL-c levels in HFD120 were 25\%, 10.7\%, and $81.6 \%$, respectively. The percentages of reduction for TG, 
TABLE 3: Effects of GE and metformin on lipid profile and AI in C57BL/6J mice fed on a high-fat diet or normal diet.

\begin{tabular}{|c|c|c|c|c|c|}
\hline \multirow{2}{*}{ Groups } & \multicolumn{5}{|c|}{ Serum concentration $(\mathrm{mmol} / \mathrm{L})$} \\
\hline & TG & $\mathrm{TC}$ & HDL-c & LDL-c & AI \\
\hline ND & $0.60 \pm 0.02^{\mathrm{ab}}$ & $2.03 \pm 0.5^{\mathrm{a}}$ & $1.87 \pm 0.05^{\mathrm{a}}$ & $0.14 \pm 0.0^{\mathrm{ab}}$ & 0.07 \\
\hline ND240 & $0.70 \pm 0.02^{b}$ & $1.80 \pm 0.4^{\mathrm{a}}$ & $1.79 \pm 0.01^{\mathrm{a}}$ & $0.01 \pm 0.0^{\mathrm{a}}$ & 0.01 \\
\hline HFD & $0.8 \pm 0.2^{\mathrm{bc}}$ & $2.80 \pm 0.3^{\mathrm{b}}$ & $2.52 \pm 0.3^{\mathrm{b}}$ & $0.38 \pm 0.1^{\mathrm{c}}$ & 0.11 \\
\hline HFD60 & $0.70 \pm 0.1^{\mathrm{b}}$ & $2.60 \pm 0.2^{\mathrm{b}}$ & $2.35 \pm 0.2^{\mathrm{b}}$ & $0.15 \pm 0.0^{\mathrm{ab}}$ & 0.11 \\
\hline HFD120 & $0.60 \pm 0.1^{\mathrm{ab}}$ & $2.50 \pm 0.2^{\mathrm{ab}}$ & $2.41 \pm 0.3^{\mathrm{b}}$ & $0.07 \pm 0.0^{\mathrm{a}}$ & 0.07 \\
\hline HFD240 & $0.60 \pm 0.4^{\mathrm{ab}}$ & $2.10 \pm 0.1^{\mathrm{a}}$ & $2.35 \pm 0.2^{\mathrm{b}}$ & $0.02 \pm 0.0^{\mathrm{a}}$ & 0.02 \\
\hline HFDMET & $0.50 \pm 0.0^{\mathrm{a}}$ & $2.60 \pm 0.3^{\mathrm{b}}$ & $2.55 \pm 0.3^{\mathrm{b}}$ & $0.18 \pm 0.0^{\mathrm{ab}}$ & 0.02 \\
\hline
\end{tabular}

Values expressed are means \pm S.D of $(n=6$ per group) measurements. For same assay with various treatment groups, superscripts in the different bar with different alphabets $(\mathrm{a}-\mathrm{c})$ were significantly different $(P<0.05)$. Superscripts with same alphabets were not significantly different between the treated groups $(P>0.05)$. TG is triglycerides; TC is total cholesterol; HDL-c is high-density lipoprotein cholesterol; LDL-c is low-density lipoprotein cholesterol; AI is atherogenic index.

TC, and LDL-c levels in HFD240 were 25\%, 25\%, and 94.7\%, respectively. However, there were no significant differences $(P>0.05)$ in the HDL-c level between the treated groups and control group. The HFDMET group showed decreased levels of TG (37.5\%), TC (7.1\%), and LDL-c (52.65\%) levels and increased level of HDL-c (1.2\%) compared to the HFD group. The AI and cardiac risk factor were calculated based on the measurement obtained from the lipid analysis. The AI was defined by TC minus HDL-c divided by HDL-c, whilst the cardiac risk factor was calculated as TC divided by HDLc [26]. In this study, the AI risk predictor indices for the HFD group were increased compared to those in ND and GE or metformin-treated groups. In accordance to the high AI risk factor, the cardiac risk factor was also elevated in the HFD group compared to those in ND and GE or metformintreated groups. The reductions in the atherogenic and cardiac risk indexes in GE-treated groups indicate a decreased risk of cardiovascular disease [27]. Beta-glucan has been shown to decrease LDL-c and increase HDL-c to alleviate possibly dyslipidemia and reduce cardiovascular disease [28]. Oats were first found to have a cholesterol-lowering effect, and the active component was identified as beta-glucans [29]. Similar serum cholesterol-lowering activity was also observed in Maitake, Shiitake, and Enokitake mushrooms [30]. The mechanism for LDL-c lowering by $\beta$-glucans is speculated to involve bile acid binding. The increased exclusion of bile acids activates cholesterol $7 \alpha$-hydroxylase and upregulates low-density lipoprotein receptor (LDLR) and thus increases the transport of LDL-c into hepatocytes and the conversion of cholesterol into bile acids [31].

3.3. Effects of GE on Liver Enzymes. Table 4 shows the effects of GE and metformin-treated groups on liver enzymes. Increased liver enzyme concentrations and activity in the serum are conventionally interpreted as a marker of liver damage. In this study, the alanine transaminase (ALT), aspartate transaminase (AST), and alkaline phosphate (ALP) levels of mice in the HFD group were significantly elevated compared to the other groups. However, there were no changes in the glutamyl transferase (GGT) level between these groups. A recent study demonstrated that obese patients with increased serum TG level showed raised levels of each of the four liver enzymes [32]. Weight reductions have been shown to reduce the liver enzyme levels [33]. The present study shows that GE confers protection against high-fat dietmediated liver damage.

3.4. Effects of GE on the Urinary Oxidative Indices. Oxidation products can be found in the urine and are considered to reflect local and systemic oxidative stress [34]. Figures 2(a)-2(c) show the AOPP, lipid hydroperoxide, and 8-OHdG levels in each group during the 16 weeks of experiment. The AOPP, lipid hydroperoxides, and 8-OHdG levels in the ND group gradually increased every week, however, these oxidative stress indices were significantly elevated in the HFD group compared with all other groups. The mice in HFD group were obese, and this may have contributed to the increased level of oxidative stress indices in the animals [35]. The AOPP and lipid hydroperoxide levels in GE-treated groups were lower compared to the HFD group, and this effect was dose dependent. Similarly, HFDMET also showed a decrease in AOPP and lipid hydroperoxide levels compared to the HFD group. The 8-OHdG level was elevated in HFD group, however, no significant differences were observed between all the groups tested $(P>0.05)$. Studies have shown that elevated levels of MDA [36], AOPP [37], and 8OHdG [38] in obese animals or humans are associated with several disease conditions including hypertension, diabetes, cardiovascular diseases, and renal diseases [39].

3.5. Effects of GE on Enzymatic Antioxidant Levels in Liver and Kidney Homogenates. Fruits, vegetables, spices, herbs, and mushrooms have been studied for their antioxidant properties in-vitro extensively $[40,41]$. However, the demonstration of the antioxidant properties of these components in-vivo is scarce but is gaining importance nowadays. Previously, antioxidant capacity has been mainly assessed in serum or plasma after an oral intake of a food infusion. Nevertheless, numerous studies have also suggested that oxidative processes occurring in various tissues and organs in the human body may be crucial in the onset of metabolic diseases [42]. It is reported that, after absorption, the antioxidant 


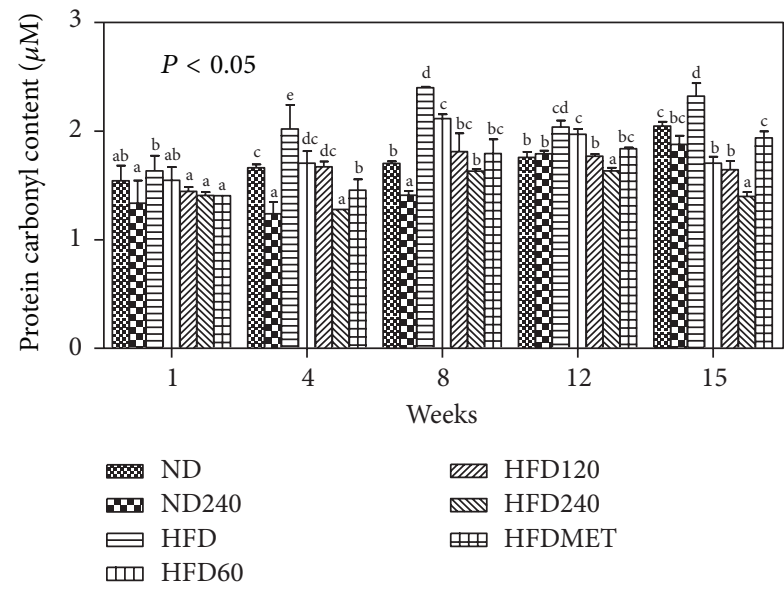

(a)

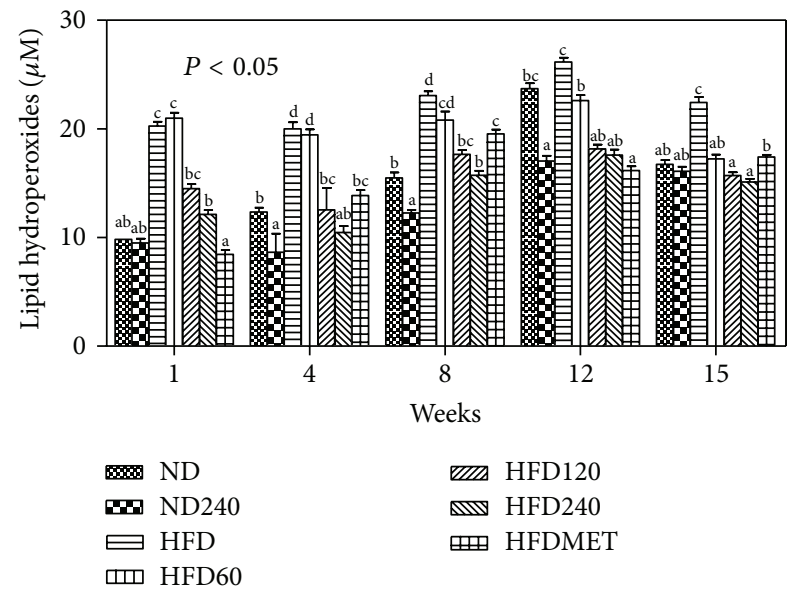

(b)

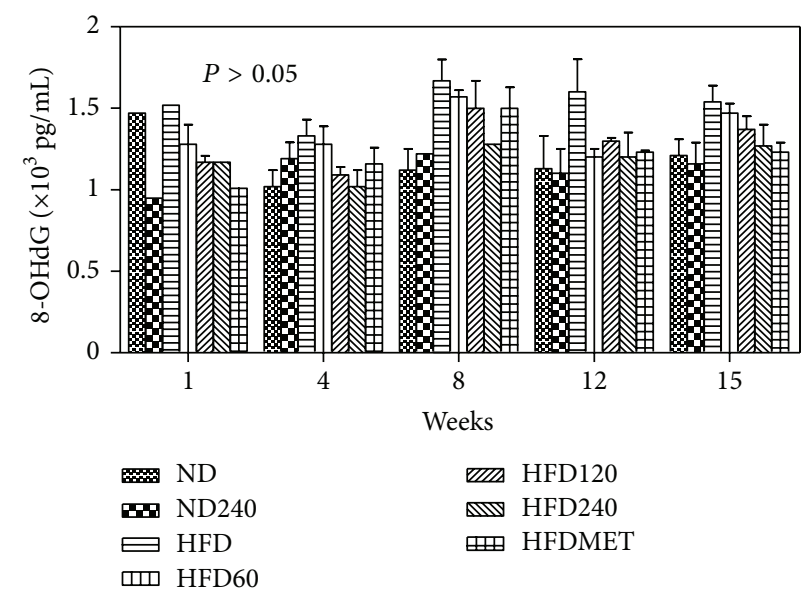

(c)

FIGURE 2: Effects of GE and metformin on (a) AOPP (b) lipid hydroperoxide, and (c) 8-OHdG levels in urine samples of C57BL/6J mice fed on a high-fat diet or normal diet. Values expressed are means \pm S.D of triplicate measurements ( $n=6$ per group). For same assay with various treatment groups, superscripts in the different bar with different alphabets (a)-(e) were significantly different $(P<0.05)$. Superscripts with same alphabets were not significantly different between the treated groups $(P>0.05)$. There was no significant difference observed in the 8 -OHdG levels between the groups tested $(P>0.05)$.

TABLE 4: Effects of GE and metformin on liver enzymes in C57BL/6J mice fed on a high-fat diet or normal diet.

\begin{tabular}{lcccc}
\hline \multirow{2}{*}{ Groups } & & \multicolumn{2}{c}{ Liver enzymes (mmol/L) } & \\
& Alanine transaminase (ALT) & Aspartate transaminase (AST) & Alkaline phosphate (ALP) & G-glutamyl transferase (GGT) \\
\hline ND & $45 \pm 1.2^{\mathrm{c}}$ & $182 \pm 11.2^{\mathrm{b}}$ & $39 \pm 1.2^{\mathrm{a}}$ & $<3$ \\
ND240 & $29 \pm 1.1^{\mathrm{a}}$ & $148 \pm 10.2^{\mathrm{a}}$ & $30 \pm 1.1^{\mathrm{a}}$ & $<3$ \\
HFD & $48 \pm 1.4^{\mathrm{c}}$ & $210 \pm 8.2^{\mathrm{c}}$ & $54 \pm 0.9^{\mathrm{c}}$ & $<3$ \\
HFD60 & $46 \pm 2.3^{\mathrm{c}}$ & $194 \pm 12.1^{\mathrm{b}}$ & $44 \pm 1.4^{\mathrm{b}}$ & $<3$ \\
HFD120 & $32 \pm 2.4^{\mathrm{b}}$ & $181 \pm 10.1^{\mathrm{b}}$ & $38 \pm 1.3^{\mathrm{a}}$ & $<3$ \\
HFD240 & $27 \pm 1.4^{\mathrm{a}}$ & $176 \pm 9.7^{\mathrm{ab}}$ & $35 \pm 1.3^{\mathrm{a}}$ & $<3$ \\
HFDMET & $39 \pm 1.33^{\mathrm{b}}$ & $189 \pm 9.5^{\mathrm{b}}$ & $39 \pm 1.5^{\mathrm{a}}$ & $<3$ \\
\hline
\end{tabular}

GE concentrations were 60,120 , and $240 \mathrm{mg} / \mathrm{kg} /$ day. Metformin (MET) is used as positive control. Values expressed are means \pm S.D of triplicate measurements. For same enzyme level with various treatment groups, superscripts in the different bar with different alphabets $(\mathrm{a}-\mathrm{c})$ were significantly different $(P<0.05)$. Superscripts with same alphabets were not significantly different between the treated groups $(P>0.05)$. 
TABLE 5: Effects of GE on enzymic antioxidants and MDA levels in the kidney and liver homogenates of C5BL/6J mice fed on a high-fat diet.

\begin{tabular}{lccccc}
\hline & Groups & & \multicolumn{2}{c}{ Antioxidant activity (nmol/min/mg protein) } \\
& & GPx & CAT & SOD (U/mg protein) & LPO (mmol/L) \\
\hline \multirow{2}{*}{ ND } & Kidney & $71.08 \pm 6.3^{\mathrm{cd}}$ & $103.93 \pm 4.5^{\mathrm{d}}$ & $0.34 \pm 0.0^{\mathrm{d}}$ & $0.89 \pm 0.01^{\mathrm{e}}$ \\
& Liver & $83.95 \pm 10.8^{\mathrm{b}}$ & $29.96 \pm 3.9^{\mathrm{c}}$ & $0.17 \pm 0.0^{\mathrm{b}}$ & $0.76 \pm 0.03^{\mathrm{b}}$ \\
\hline \multirow{2}{*}{ ND240 } & Kidney & $82.72 \pm 6.9^{\mathrm{d}}$ & $112.96 \pm 4.6^{\mathrm{e}}$ & $0.37 \pm 0.0^{\mathrm{d}}$ & $0.83 \pm 0.04^{\mathrm{d}}$ \\
& Liver & $90.42 \pm 11.7^{\mathrm{b}}$ & $32.57 \pm 6.7^{\mathrm{d}}$ & $0.32 \pm 0.0^{\mathrm{d}}$ & $0.7 \pm 0.1^{\mathrm{b}}$ \\
\hline \multirow{2}{*}{ HFD } & Kidney & $32.31 \pm 3.2^{\mathrm{a}}$ & $52.64 \pm 1.2^{\mathrm{a}}$ & $0.017 \pm 0.0^{\mathrm{a}}$ & $0.9 \pm 0.04^{\mathrm{e}}$ \\
& Liver & $45.22 \pm 5.5^{\mathrm{a}}$ & $15.18 \pm 8.7^{\mathrm{a}}$ & $0.01 \pm 0.0^{\mathrm{a}}$ & $0.92 \pm 0.1^{\mathrm{c}}$ \\
\hline \multirow{2}{*}{ HFD60 } & Kidney & $32.46 \pm 4.9^{\mathrm{a}}$ & $79.72 \pm 1.3^{\mathrm{b}}$ & $0.23 \pm 0.0^{\mathrm{b}}$ & $0.86 \pm 0.02^{\mathrm{de}}$ \\
& Liver & $68.20 \pm 8.3^{\mathrm{b}}$ & $22.98 \pm 5.7^{\mathrm{b}}$ & $0.19 \pm 0.0^{\mathrm{b}}$ & $0.62 \pm 0.1^{\mathrm{a}}$ \\
\hline \multirow{2}{*}{ HFD120 } & Kidney & $36.16 \pm 5.1^{\mathrm{ab}}$ & $86.40 \pm 11.6^{\mathrm{bc}}$ & $0.27 \pm 0.0^{\mathrm{c}}$ & $0.64 \pm 0.03^{\mathrm{b}}$ \\
& Liver & $74.86 \pm 8.7^{\mathrm{b}}$ & $24.91 \pm 9.7^{\mathrm{bc}}$ & $0.23 \pm 0.0^{\mathrm{bc}}$ & $0.6 \pm 0.04^{\mathrm{a}}$ \\
\hline \multirow{2}{*}{ HFD240 } & Kidney & $44.58 \pm 5.3^{\mathrm{b}}$ & $84.29 \pm 1.5^{\mathrm{bc}}$ & $0.22 \pm 0.0^{\mathrm{b}}$ & $0.26 \pm 0.0^{\mathrm{c}}$ \\
\hline \multirow{2}{*}{ HFDMET } & Liver & $61.39 \pm 8.9^{\mathrm{b}}$ & $24.30 \pm 1.1^{\mathrm{bc}}$ & $0.04^{\mathrm{a}}$ \\
& Kidney & $66.83 \pm 5.5^{\mathrm{c}}$ & $89.49 \pm 2.7^{\mathrm{c}}$ & $0.20 \pm 0.0^{\mathrm{b}}$ & $0.61 \pm 0.06^{\mathrm{a}}$ \\
\hline
\end{tabular}

GE concentrations were 60,120 , and $240 \mathrm{mg} / \mathrm{kg} /$ day. Metformin (MET) is used as positive control. Values expressed are means \pm S.D of triplicate measurements. For same antioxidant activity with various treatment groups, superscripts in the different bar with different alphabets (a-e) were significantly different $(P<0.05)$. Superscripts with same alphabets were not significantly different between the treated groups $(P>0.05)$. GPx is glutathione peroxidase; CAT is catalase; SOD is superoxide dismutase; LPO is lipid peroxidation.

compounds are transferred through the blood circulation to various organs [43]. In the present study, the enzymic antioxidant activities and LPO level were assessed in the liver and kidney homogenates (Table 5), since these are the key organs in the mammalian oxidative metabolism. The natural antioxidant system consists of a series of antioxidant enzymes and numerous endogenous and dietary antioxidant compounds that react with and inactivate ROS. The primary antioxidant enzymes include SOD, CAT, and GPx. Meanwhile, the nonenzymatic antioxidants include vitamin $\mathrm{C}$, vitamin $\mathrm{E}, \beta$-carotene, reduced glutathione (GSH), and numerous phytochemicals. Cells must maintain their levels of antioxidants, often defined as their antioxidant potential, through dietary intake and/or de novo synthesis [44, 45]. Increased levels of ROS in cells and tissues may act as a signal to enhance the activity and expression of antioxidant enzymes. A high-fat diet is known to increase the superoxide anion $\left(\mathrm{O}_{2}{ }^{--}\right)$radicals in the body. Superoxide dismutase converts the $\mathrm{O}_{2}{ }^{--}$radicals to hydrogen peroxide $\left(\mathrm{H}_{2} \mathrm{O}_{2}\right)$ which in turn is converted to water by CAT and GPx. In this study, the HFD group showed reduced levels of SOD, CAT, and GPx activities in the kidney and liver homogenates compared to the ND group. Whereas, GE- and metformin-treated groups showed increased levels of SOD, GPx, and CAT activities compared to the control groups (ND and HFD) (Table 4). Overall, the increased level of antioxidant enzyme activities in GE- and metformin-treated groups conferred protection against oxidative damages in the mice, and this speculation is supported by the attenuated levels of oxidative stress indices such as AOPP and lipid hydroperoxide levels in the urine as well as MDA level in the kidney and liver homogenates.

3.6. Effects of $G E$ on the Expression of Differentiation and Lipolysis Genes in Adipose Tissue. Adipose tissue is a complex and active secretory organ that both sends and receives signals that modulate energy expenditure, appetite, insulin sensitivity, endocrine function, inflammation, and immunity [46]. Table 6 shows the expression of the selected genes involved in the differentiation and lipolysis processes in adipose tissue. The mice fed on a high-fat diet (HFD group) weighed more and developed substantially more adipose tissue than the mice on a normal diet (ND group) (Figure 1). The mice became hyperlipidemic, and this is typically associated with obesity [47] (Table 3). PPAR- $\gamma$ and SREBP-1c genes are the key adipose transcription factors that play important roles in lipogenesis [48]. These genes act cooperatively and sequentially to trigger terminal adipocyte differentiation. The PPAR- $\gamma$ is expressed selectively in the adipose tissues, and it promotes the differentiation and proliferation of the preadipocytes thereby causing an increase in fat mass [49], while SREBP-1c controls the production of endogenous ligands for PPAR- $\gamma$ as a mechanism for coordinating the actions of these adipogenic factors [48] and has been implicated as being a key regulator for fatty acid and triglyceride synthesis [50]. Meanwhile, LPL is the key enzyme that regulates the disposal of lipid in the body, and its role is to hydrolyse triglyceride circulating in the lipoprotein particles in order to facilitate the uptake fatty acids into the cells [51]. GEtreated groups had lower expression of PPAR- $\gamma$, SREBP-1c, and LPL compared to HFD group. PPAR- $\gamma$ protein binds to the promoter regions of adipocyte-expressed LPL gene [52], and the attenuation of PPAR- $\gamma$ gene expression in GE-treated groups could have attributed to the reduced expression of LPL as well. HSL and ATGL genes are reported to play an important role in the mobilization of stored triacylglycerol (TAG) [53]. The activation of these genes leads to mobilization of TAG to form glycerol and fatty acids where HSL mainly breaks down TAG to form diacylglycerol (DAG) whilst ATGL breaksdown DAG to form monoacylglycerol (MAG). Subsequently, MAG is converted to free fatty acids 
TABLE 6: Effects of GE on the expression of genes in adipose tissue.

\begin{tabular}{|c|c|c|c|c|c|}
\hline Genes investigated & ND240 & HFD60 & HFD120 & HFD240 & HFDMET \\
\hline \multicolumn{6}{|l|}{ Lipolysis } \\
\hline ATGL & $1.34 \pm 0.34$ & $1.78 \pm 0.67^{\mathrm{a}}$ & $6.05 \pm 0.42^{c}$ & $5.69 \pm 0.34^{\mathrm{c}}$ & $3.84 \pm 0.98^{\mathrm{b}}$ \\
\hline HSL & $1.98 \pm 0.07$ & $2.99 \pm 0.17^{\mathrm{a}}$ & $6.73 \pm 0.42^{c}$ & $6.54 \pm 0.32^{c}$ & $4.63 \pm 1.16^{\mathrm{b}}$ \\
\hline \multicolumn{6}{|l|}{ Differentiation } \\
\hline LPL & $-1.05 \pm 0.09$ & $-1.93 \pm 0.18^{\mathrm{a}}$ & $-1.12 \pm 0.42^{\mathrm{b}}$ & $-1.17 \pm 0.47^{\mathrm{b}}$ & $-2.22 \pm 0.99^{\mathrm{a}}$ \\
\hline PPAR- $\gamma$ & $-1.69 \pm 0.19$ & $-2.08 \pm 0.69^{\mathrm{a}}$ & $-1.69 \pm 0.48^{\mathrm{ab}}$ & $-1.02 \pm 0.36^{\mathrm{c}}$ & $-1.07 \pm 0.16^{\mathrm{c}}$ \\
\hline SREBP-1c & $-1.27 \pm 0.65$ & $-1.01 \pm 0.16^{\mathrm{c}}$ & $-3.10 \pm 0.44^{\mathrm{a}}$ & $-2.25 \pm 0.30^{\mathrm{ab}}$ & $-2.30 \pm 1.13^{\mathrm{ab}}$ \\
\hline
\end{tabular}

Results are expressed as fold variation over the appropriate control groups; ND240 indicates fold increase over ND (normal diet control group), and HFD60, HFD120, HFD240, and HFDMET indicate fold increase over HFD (high-fat diet control group). Fold variations less than one were expressed as negative numbers (e.g., a fold variation of 0.50 is expressed as -2.00 ). Values expressed are means \pm S.D of triplicate measurements. Statistical significance was calculated based on the mean $\triangle \mathrm{CT}$ values by DMRT for only mice fed with high-fat diet with or without GE. For same gene with various treatment groups, superscripts in the different bar with different alphabets $(\mathrm{a}-\mathrm{c})$ were significantly different $(P<0.05)$. Superscripts with same alphabets were not significantly different between the treated groups $(P>0.05)$.

and glycerol by monoacylglycerol lipase (MGL) [54]. The GEtreated groups had significantly upregulated expressions of HSL and ATGL genes, and the effect was dose dependent. Therefore, it is feasible to suggest that the reduced weight gain in the high-fat diet fed mice treated with GE was due to the reduced adipose differentiation and increased lipolysis in adipocytes.

\section{Conclusion}

Previous studies have demonstrated that the lipid lowering potential of $\beta$-glucans was mainly mediated by either bile acid binding, delay in the digestion/absorption of fat, or suppressed appetite. However, in this study, GE prevented weight gain and hyperlipidemia in $\mathrm{C} 57 \mathrm{BL} / 6 \mathrm{~J}$ mice fed on a high-fat diet by inducing lipolysis and inhibiting the differentiation of adipocytes. GE also prevented oxidative stress caused by obesity by increasing the enzymic antioxidant activities, hence, GE could serve as a potential candidate for the management of obesity.

\section{Conflict of Interests}

The authors declare that they have no conflict of interests.

\section{Acknowledgments}

The authors are grateful to the University of Malaya and the Ministry of Higher Education (MOHE), Malaysia, for providing the following grants: RG083-09AFR and HIR F000002-21001.

\section{References}

[1] B. M. Spiegelman and J. S. Flier, "Obesity and the regulation of energy balance," Cell, vol. 104, no. 4, pp. 531-543, 2001.

[2] J. W. Yun, "Possible anti-obesity therapeutics from nature- a review," Phytochemistry, vol. 71, no. 14-15, pp. 1625-1641, 2010.

[3] H. Choi, H. Eo, K. Park et al., "A water soluble extract from Curcubita mocshata shows anti-obesity effects by controlling lipid metabolism in high fat diet-induced obesity mouse model,"
Biochemical and Biophysical Research Communications, vol. 359, no. 3, pp. 419-425, 2007.

[4] D. Haslam, "Obesity and diabetes: the links and common approaches," Primary Care Diabetes, vol. 4, no. 2, pp. 105-112, 2010.

[5] G. A. Kennett and P. G. Clifton, "New approaches to the pharmacological treatment of obesity: can they break through the efficacy barrier?" Pharmacology Biochemistry and Behavior, vol. 97, no. 1, pp. 63-83, 2010.

[6] L. Slovacek, V. Pavlik, and B. Slovackova, "The effect of sibutramine therapy on occurrence of depression symptoms among obese patients," Nutrition, Metabolism and Cardiovascular Diseases, vol. 18, no. 8, pp. e43-e44, 2008.

[7] C. Zou and J. Shao, "Role of adipocytokines in obesityassociated insulin resistance," Journal of Nutritional Biochemistry, vol. 19, no. 5, pp. 277-286, 2008.

[8] Y. Ono, E. Hattori, Y. Fukaya, S. Imai, and Y. Ohizumi, "Antiobesity effect of Nelumbo nucifera leaves extract in mice and rats," Journal of Ethnopharmacology, vol. 106, no. 2, pp. 238-244, 2006.

[9] Y. W. Huang, Y. Liu, S. Dushenkov, C. T. Ho, and M. T. Huang, "Anti-obesity effects of epigallocatechin-3-gallate, orange peel extract, black tea extract, caffeine and their combinations in a mouse model," Journal of Functional Foods, vol. 1, no. 3, pp. 304310, 2009.

[10] A. Golay and J. Ybarra, "The link between obesity and type 2 diabetes," Best Practice \& Research Clinical Endocrinology \& Metabolism, vol. 19, no. 4, pp. 649-663, 2005.

[11] S. Furukawa, T. Fujita, M. Shimabukuro et al., "Increased oxidative stress in obesity and its impact on metabolic syndrome," Journal of Clinical Investigation, vol. 114, no. 12, pp. 1752-1761, 2004.

[12] M. Curzio, H. Esterbauer, and G. Poli, "Possible role of aldehydic lipid peroxidation products as chemoattractants," International Journal of Tissue Reactions, vol. 9, no. 4, pp. 295306, 1987.

[13] V. Witko-Sarsat, M. Friedlander, T. N. Khoa et al., "Advanced oxidation protein products as novel mediators of inflammation and monocyte activation in chronic renal failure," Journal of Immunology, vol. 161, no. 5, pp. 2524-2532, 1998.

[14] S. P. Wasser, "Current findings, future trends, and unsolved problems in studies of medicinal mushrooms," Applied Microbiology and Biotechnology, vol. 89, no. 5, pp. 1323-1332, 2001. 
[15] I. Schneider, G. Kressel, A. Meyer, U. Krings, R. G. Berger, and A. Hahn, "Lipid lowering effects of oyster mushroom (Pleurotus ostreatus) in humans," Journal of Functional Foods, vol. 3, no. 1, pp. 17-24, 2011.

[16] G. Kanagasabapathy, U. R. Kuppusamy, S. N. A. Malek, A. A. Mahmood, K. H. Chua, and V. Sabaratnam, "Glucan-rich polysaccharides from Pleurotus sajor-caju (Fr.) Singer prevent glucose intolerance, insulin resistance and inflammation in C57BL/6J mice fed a high-fat diet," BMC Complementary and Alternative Medicine, vol. 12, p. 261, 2012.

[17] D. Khoury, C. Cuda, B. L. Luhovyy, and G. H. Anderson, "Beta Glucan: health benefits in obesity and metabolic syndrome," Journal of Nutrition and Metabolism, vol. 2012, Article ID 851362, 28 pages, 2012.

[18] S. K. Roy, D. Maiti, S. Mondal, D. Das, and S. S. Islam, "Structural analysis of a polysaccharide isolated from the aqueous extract of an edible mushroom, Pleurotus sajor-caju, cultivar Black Japan," Carbohydrate Research, vol. 343, no. 6, pp. 1108$1113,2008$.

[19] A. Gokcel, Y. Gumurdulu, H. Karakose et al., "Evaluation of the safety and efficacy of sibutramine, orlistat and metformin in the treatment of obesity," Diabetes, Obesity and Metabolism, vol. 4, no. 1, pp. 49-55, 2002.

[20] U. R. Kuppusamy and N. P. Das, "Potentiation of $\beta$-adrenoceptor agonist-mediated lipolysis by quercetin and fisetin in isolated rat adipocytes," Biochemical Pharmacology, vol. 47, no. 3, pp. 521-529, 1994.

[21] H. Esterbauer and K. H. Cheeseman, "Determination of aldehydic lipid peroxidation products: malonaldehyde and 4hydroxynonenal," Methods in Enzymology, vol.186, pp. 407-421, 1990.

[22] M. M. Bradford, "A rapid and sensitive method for the quantitation of microgram quantities of protein utilizing the principle of protein dye binding," Analytical Biochemistry, vol. 72, no. 1-2, pp. 248-254, 1976.

[23] U. R. Kuppusamy, M. Indran, and P. Rokiah, "Glycaemic control in relation to xanthine oxidase and antioxidant indices in Malaysian Type 2 diabetes patients," Diabetic Medicine, vol. 22, no. 10, pp. 1343-1346, 2005.

[24] K. J. Livak and T. D. Schmittgen, "Analysis of relative gene expression data using real-time quantitative PCR and the 2$\Delta \Delta$ CT method," Methods, vol. 25, no. 4, pp. 402-408, 2001.

[25] J. Chen and K. Raymond, "Beta-glucans in the treatment of diabetes and associated cardiovascular risks," Vascular Health and Risk Management, vol. 4, no. 6, pp. 1265-1272, 2008.

[26] T. N. Kasaoka, M. Takahashi, H. Kim, and O. Ezaki, "Upregulation of liver uncoupling protein-2 mRNA by either fish oil feeding or fibrate administration in mice," Biochemical and Biophysical Research Communications, vol. 257, no. 3, pp. 879885, 1999.

[27] J. H. Keefe and D. S. H. Bell, "Postprandial hyperglycemia/ hyperlipidemia is a cardiovascular risk factor," American Journal of Cardiology, vol. 100, no. 5, pp. 899-904, 2007.

[28] N. K. Kapur, D. Ashen, and R. S. Blumenthal, "High density lipoprotein cholesterol: an evolving target of therapy in the management of cardiovascular disease," Vascular Health and Risk Management, vol. 4, no. 1, pp. 39-57, 2008.

[29] D. A. J. M. Kerckhoffs, G. Hornstra, and R. P. Mensink, "Cholesterol-lowering effect of beta-glucan from oat bran in mildly hypercholesterolemic subjects may decrease when $\beta$ glucan is incorporated into bread and cookies," American Journal of Clinical Nutrition, vol. 78, no. 2, pp. 221-227, 2003.
[30] M. Fukushima, T. Ohashi, Y. Fujiwara, K. Sonoyama, and M. Nakano, "Cholesterol-lowering effects of maitake (Grifola frondosa) fiber, shiitake (Lentinus edodes) fiber, and enokitake (Flammulina velutipes) fiber in rats," Experimental Biology and Medicine, vol. 226, no. 8, pp. 758-765, 2001.

[31] L. M. Nilsson, A. Abrahamsson, S. Sahlin et al., "Bile acids and lipoprotein metabolism: effects of cholestyramine and chenodeoxycholic acid on human hepatic mRNA expression," Biochemical and Biophysical Research Communications, vol. 357, no. 3, pp. 707-711, 2007.

[32] M. Nannipieri, C. Gonzales, S. Baldi et al., "Liver enzymes, the metabolic syndrome, and incident diabetes: the Mexico City diabetes study," Diabetes Care, vol. 28, no. 7, pp. 1757-1762, 2005.

[33] S. Parekh and F. A. Anania, "Abnormal lipid and glucose metabolism in obesity: implications for nonalcoholic fatty liver disease," Gastroenterology, vol. 132, no. 6, pp. 2191-2207, 2007.

[34] B. Kircshbaum, "Total urine antioxidant capacity" Clinica Chimica Acta, vol. 305, no. 1-2, pp. 167-173, 2001.

[35] F. Galli, M. Piroddi, C. Annetti, C. Aisa, E. Floridi, and A. Floridi, "Oxidative stress and reactive oxygen species," Contributions to Nephrology, vol. 149, pp. 240-260, 2005.

[36] R. Agarwal and S. D. Chase, "Rapid flurometric-liquid chromatographic determination of malondialehyde in biological samples," Journal of Chromatography B, vol. 775, no. 1, pp. 121126, 2002.

[37] M. Nagata, T. Takamura, H. Ando et al., "Increased oxidative stress precedes the onset of high-fat diet-induced insulin resistance and obesity," Metabolism, vol. 57, no. 8, pp. 1071-1077, 2008.

[38] L. L. Wu, C. C. Chiou, P. Y. Chang, and J. T. Wu, "Urinary 8OHdG: a marker of oxidative stress to DNA and a risk factor for cancer, atherosclerosis and diabetics," Clinica Chimica Acta, vol. 339, no. 1-2, pp. 1-9, 2004.

[39] G. Yoshino, M. Tanaka, S. Nakano et al., "Effect of rosvastatin on concentration of plasma lipids, urine and plasma oxidative stress markers, and plasa high-sansitivity c-reactive proteins in hypercholesterolemic patients," Current Therapeutic Research, vol. 6, no. 6, pp. 439-448, 2009.

[40] G. Kanagasabapathy, S. N. A. Malek, U. R. Kuppusamy, and S. Vikineswary, "Chemical composition and antioxidant properties of extracts of fresh fruiting bodies of Pleurotus sajor-caju (Fr.) singer," Journal of Agricultural and Food Chemistry, vol. 59, no. 6, pp. 2618-2626, 2011.

[41] I. Palacios, M. Lozano, C. Moro et al., "Antioxidant properties of phenolic compounds occurring in edible mushrooms," Food Chemistry, vol. 128, no. 3, pp. 674-678, 2011.

[42] L. G. Wood, P. G. Gibson, and M. L. Garg, "A review of the methodology for assessing in vivo antioxidant capacity," Journal of the Science of Food and Agriculture, vol. 86, no. 13, pp. 20572066, 2006.

[43] V. M. Castrillejo, M. M. Romero, M. Esteve, A. Ardevol, M. Blay, C. Blade et al., "Antioxidant effect of grape seed procyanidin extract and oleoyl-estrone in obese Zucker rats," Nutrition, vol. 27, no. 11-12, pp. 1172-1176, 2011.

[44] C. K. Roberts and K. K. Sindhu, "Oxidative stress and metabolic syndrome," Life Sciences, vol. 84, no. 21-22, pp. 705-712, 2009.

[45] J. L. Rains and S. K. Jain, "Oxidative stress, insulin signaling and diabetes," Free Radical Biology and Medicine, vol. 50, no. 5, pp. 567-575, 2011.

[46] S. E. Shoelson, L. Herrero, and A. Naaz, "Obesity, inflammation, and insulin resistance," Gastroenterology, vol. 132, no. 6, pp. 2169-2180, 2007. 
[47] H. J. Harwood, "The adipocyte as an endocrine organ in the regulation of metabolic homeostasis," Neuropharmacology, vol. 63, no. 1, pp. 57-75, 2012.

[48] R. P. Brun, J. B. Kim, E. Hu, and B. M. Spiegelman, "Peroxisome proliferator-activated receptor gamma and the control of adipogenesis," Current Opinion in Lipidology, vol. 8, no. 4, pp. 212-218, 1997.

[49] Y. J. Kim and T. Park, "Genes are differentially expressed in the epididymal fat of rats rendered obese by a high-fat diet," Nutrition Research, vol. 28, no. 6, pp. 414-422, 2008.

[50] H. Al-Hasani and H. G. Joost, "Nutrition-/diet-induced changes in gene expression in white adipose tissue," Best Practice and Research, vol. 19, no. 4, pp. 589-603, 2005.

[51] B. A. Fielding and K. N. Frayn, "Lipoprotein lipase and the disposition of dietary fatty acids," British Journal of Nutrition, vol. 80, no. 6, pp. 495-502, 1998.

[52] H. Lee, R. Kang, and Y. Yoon, "SH21B, an anti-obesity herbal composition, inhibits fat accumulation in 3T3-L1 adipocytes and high fat diet-induced obese mice through the modulation of the adipogenesis pathway," Journal of Ethnopharmacology, vol. 127, no. 3, pp. 709-717, 2010.

[53] J. W. E. Jocken, E. E. Blaak, C. J. H. van der Kallen, M. A. van Baak, and W. H. M. Saris, "Blunted $\beta$-adrenoceptor-mediated fat oxidation in overweight subjects: a role for the hormonesensitive lipase gene," Metabolism, vol. 57, no. 3, pp. 326-332, 2008.

[54] J. W. E. Jocken and E. E. Blaak, "Catecholamine-induced lipolysis in adipose tissue and skeletal muscle in obesity," Physiology and Behavior, vol. 94, no. 2, pp. 219-230, 2008. 


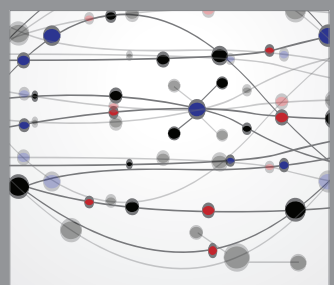

The Scientific World Journal
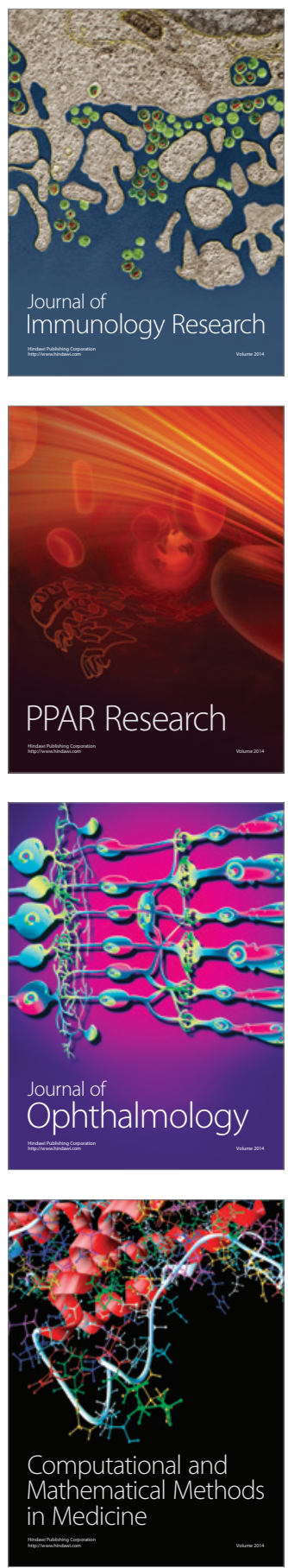

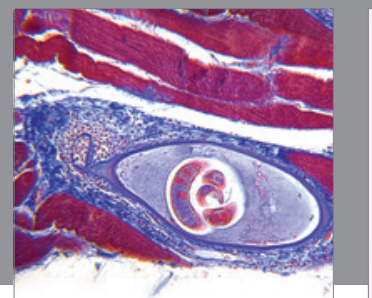

Gastroenterology

Research and Practice
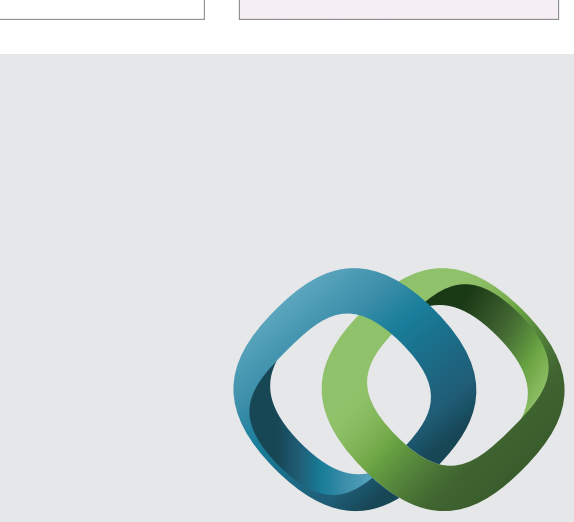

\section{Hindawi}

Submit your manuscripts at

http://www.hindawi.com
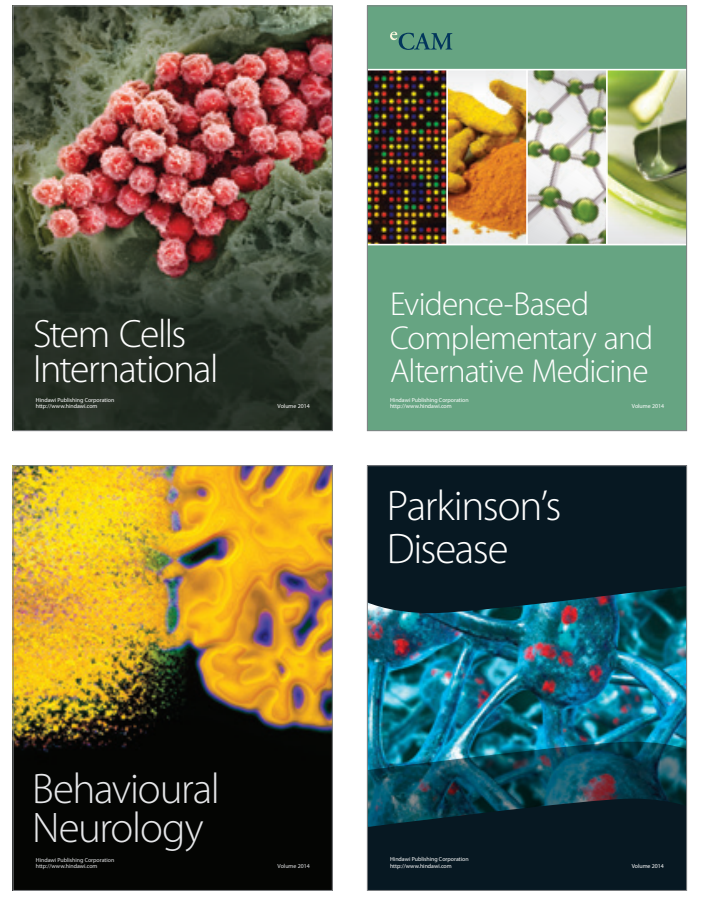
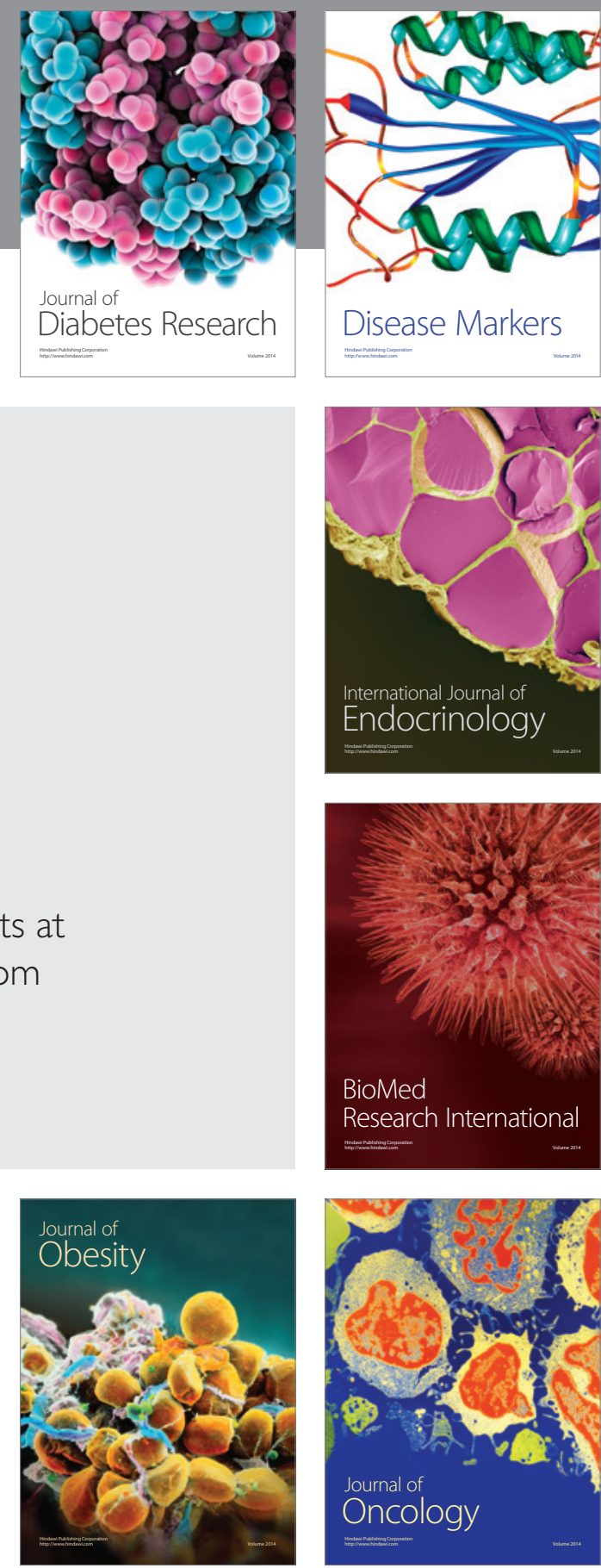

Disease Markers
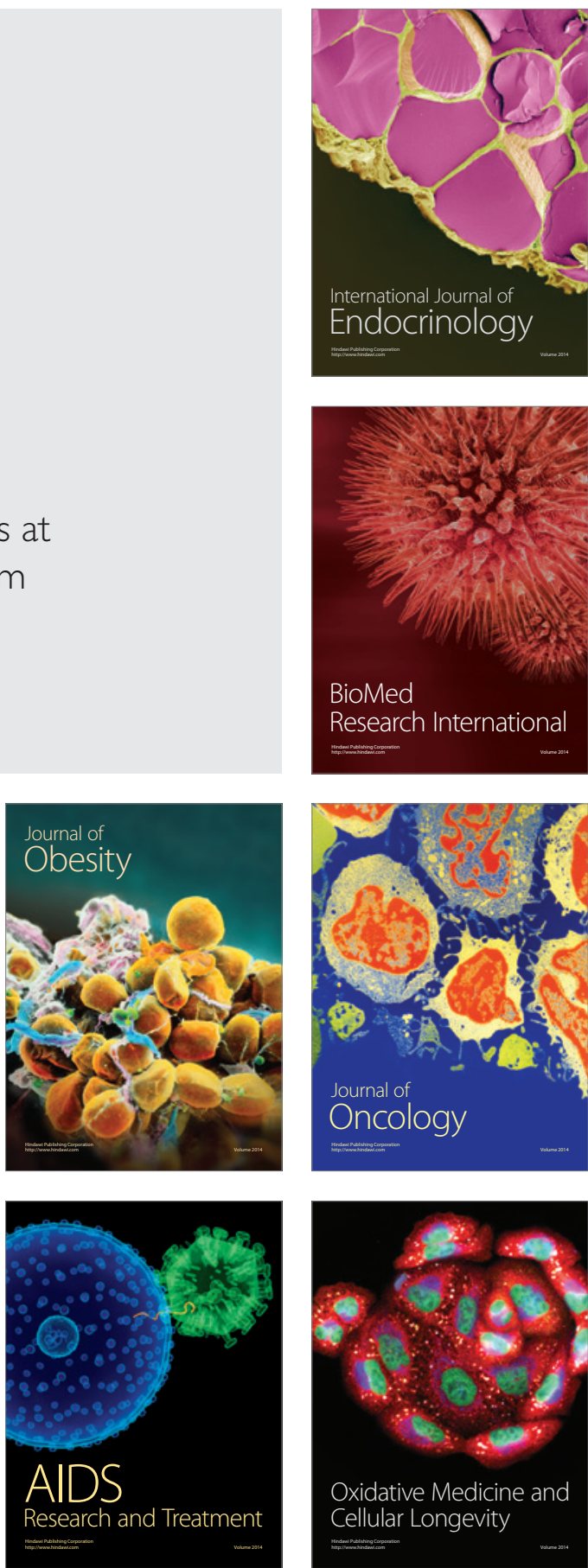